\title{
NEW FACILITY SHIELD DESIGN CRITERIA
}

\section{Hanford Engineering Development Laboratory}

W.P. Howell

July 1981

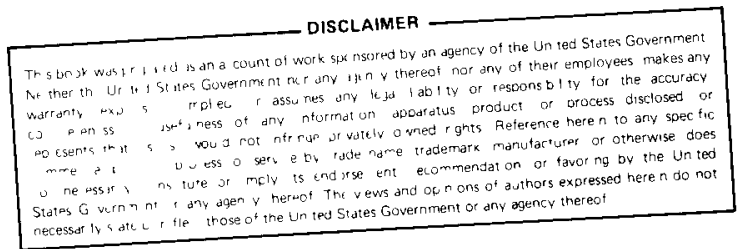

MGW

HANFORD ENGINEERING DEVELOPMENT LABORATORY

Operated by Westinghouse Hanford Company

P.O. Box 1970 Richland, WA 99352

A Subsidiary of Westinghouse Electric Corporation

Prepared for the U.S. Department of Energy under Contract No. DE-AC1476FF02170 


\section{DISCLAIMER}

This report was prepared as an account of work sponsored by an agency of the United States Government. Neither the United States Government nor any agency Thereof, nor any of their employees, makes any warranty, express or implied, or assumes any legal liability or responsibility for the accuracy, completeness, or usefulness of any information, apparatus, product, or process disclosed, or represents that its use would not infringe privately owned rights. Reference herein to any specific commercial product, process, or service by trade name, trademark, manufacturer, or otherwise does not necessarily constitute or imply its endorsement, recommendation, or favoring by the United States Government or any agency thereof. The views and opinions of authors expressed herein do not necessarily state or reflect those of the United States Government or any agency thereof. 


\section{DISCLAIMER}

Portions of this document may be illegible in electronic image products. Images are produced from the best available original document. 


\section{TABLE OF CONTENTS}

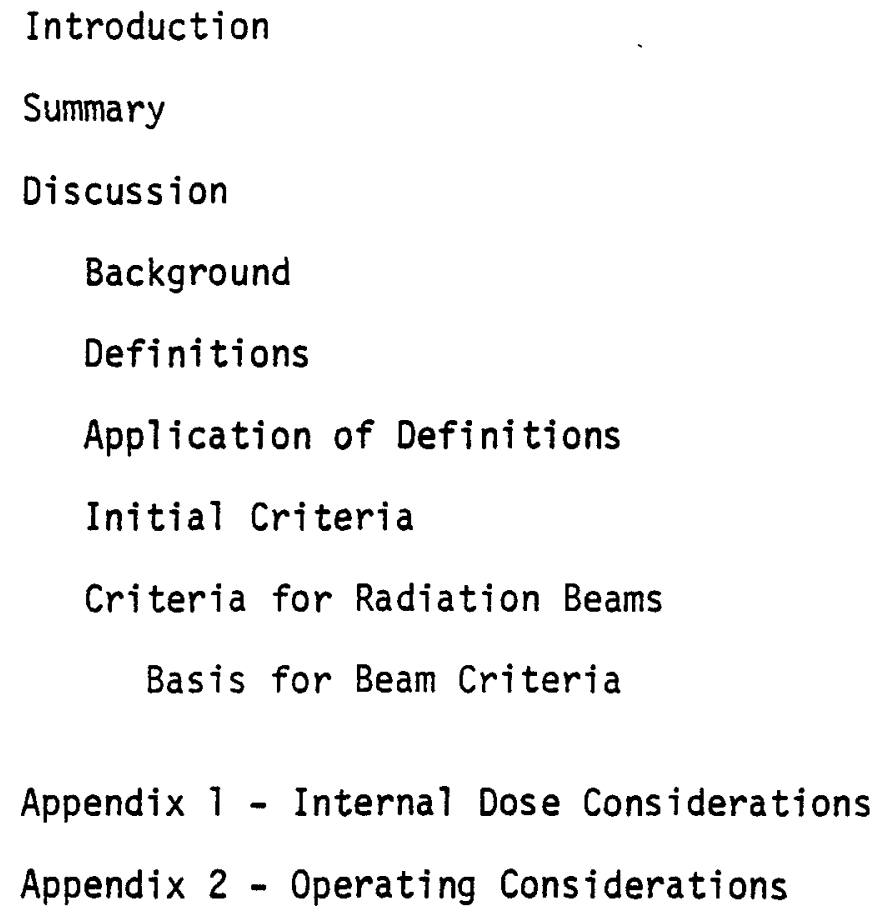




\section{New Facility Shield Design Criteria}

It is the stated policy of the Department of Energy that nuclear facility operations be conducted in a manner to assure that radiation exposure to individuals and population groups is limited to the lowest reasonably achievable levels. An important related premise is that consideration given to reduction of personnel radiation exposure during design or modification of facilities and equipment will be instrumental in maintaining exposures as low as reasonably achievable. The current whole body dose (occupational) of a radiation worker is not to exceed 5 rem per year. However, the statement of current DOE policy on new facility design in DOE Order 5480.1, Chapter XI, Page 14 is:

"On-Site personnel exposure levels less than one fifth of the permissible dose equivalent limits prescribed in this chapter should be used as a design objective."

A similar statement is also made in ERDAM Appendix 6301 [Part II, B.6.f(1)]. From the standpoint of operating economics, the size of the operating crew is not to be dictated by radiation exposure conditions. Furthermore, the rotation of crew members is not to be utilized in the design to equalize exposures throughout the entire crew. The purpose of the criteria presented here is to provide standard guidance for the design of nuclear radiation shields throughout new facilities. These criteria are required to assure a consistent and integrated design that can be operated safely and economically within the DOE standards. The scope of this report is confined to the consideration of radiation shielding for contained sources. The whole body dose limit established by the DOE applies to all doses which are generally distributed throughout the trunk of the body. Therefore, where the whole body is the critical organ for an internally deposited radionuclide, the whole body dose limit applies to the sum of doses received from both internal and external sources. Design of facilities must assure control of the concentration of radionuclides in the building atmosphere and thereby limit the dose from internal sources. The criteria in this report assume that the potential for internal deposition of radionuclides will be considered, and where appropriate, a suitable increment of the design basis dose of $1000 \mathrm{mrem}$ per year per individual will be allotted for internal dose. (See discussion in Appendix 1) 
Page 2

Summary

Within new facilities, three types of areas will be employed for radiological design purposes: uncontrolled areas, controlled access areas, and normally inaccessible areas. The facility is to be designed to limit radiation levels in uncontrolled areas to less than 0.1 mrem per hour during normal operation, normal shutdown, and normal maintenance activities, including breakdown maintenance. Controlled access areas include both controlled zones and radiation zones. Controlled zones are hallways, corridors, offices and control rooms which are adjacent to radiation zones and serve as "buffer" zones. Design radiation levels there are between 0.2 mrem per hour and $0.5 \mathrm{mrem}$ per hour. Radiation zones in the controlled access areas have design radiation levels between 0.2 mrem per hour and 1000 mrem per hour. Essentially all of the radiation work will be performed in the controlled access areas. Normally inaccessible areas are those radiation zones of the facilities in which the design radiation levels exceed 1000 mrem per hour during normal operation and/ or shutdown of the facilities. Access to these areas is permitted only under compelling circumstances. For preliminary design purposes, the following guidelines are to be employed for radiation zones, where access is based upon exposure to an individual radiation worker. Dose rates in all cases are at the point of exposure. That is, where an individual will actually be working and some, or all of his body will be exposed to radiation.

Table I

Preliminary Shield Design Criteria

Zone

Category

1

2

3

4

5

6
Access Time Allowed

Full Time

Less than 1 hour per day

Less than 1 hour per week

Less than 5 hours per year

Less than 1 hour per year

No normal access permitted
Initial Design Level Maximum (mrem per hour)

$\begin{array}{cc}0.2 & 0.5 \\ 2 & 5 \\ 10 & 20 \\ 100 & 200 \\ 500 & 1000 \\ >1000 & \end{array}$

Although Table 1 lists the maximum radiation levels for each Zone Category, the initial design effort should be directed to the lower radiation level in each case. Initial design levels are shown as guidelines, but this does not preclude designing to a lower radiation level. 
Page 3

The final design criteria to be derived from preliminary design information are to be based on the relation:

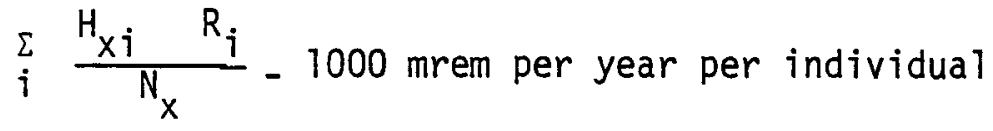

Where the summation is over all the controlled zones and radiation zones that are identified, $\mathrm{H}_{x j}$ is the total number of hours per year that all persons in craft or skill group $x$ are projected to work in the $i$-th controlled zone or radiation zone whose intensity is $R_{i}$ mrem per hour, and $N_{x}$ is the number of members in the new facility crew who belong to craft or skill group $x$. Equalization of exposure is permitted among crew members in the facility who are normally assigned to do radiation work, but rotation with outside personnel is not permitted. Note that the total allowable dose includes an appropriate increment for internal dose, where applicable. The projected exposure times for each group are based upon anticipated activities for each year of normal operation.

\section{Background}

Radiation protection standards applicable to those DOE contractor activities not subject to licensing are contained in DOE Order 5480.1, Chapter XI. It is DOE policy that operations be conducted in a manner to assure that radiation doses to individuals and population groups are limited to the lowest levels reasonably achievable. DOE standards are consistent with NRC regulations in Title 10, Code of Federal Regulations, Chapter I, Part 20, as well as with guidance provided by the National Council on Radiation Protection and Measurement (NCRP) and the International Commission on Radiological Protection (ICRP). The standard for whole body dose of individuals in areas to which access is under control of the DOE or contractor is a 1 imit of 5 rem per year. The DOE criteria do not directly establish weekly, daily, or hourly dose accumulation limits for use in the operation of a specific facility, and this kind of information must be included in the operating and maintenance procedures for the facility. Assuming that this information has been properly integrated into the facility design and into the facility procedures, adherence to the procedures will provide reasonable assurance of compliance with the basic radiation protection limits. Such procedures must be written for each facility, taking into account the radiation exposure conditions which will exist there. Operational controls and procedures will be required for any new facility to establish acceptable methods of measuring, controliing, 
and recording the radiation dose received by facility personnel and visitors during normal operation, maintenance activities and emergency conditions.

To design a new facility within the Timitations of DOE Order 5480.1 Chapter $X I$ and ERDAM 63n1, it is necessary to employ specific design criteria. Design criteria must include consideration of the number of employes that will be required to operate and maintain the facility, the types of radiation work that will be performed, the length of time required to perform specific radiation work, the frequency of the work, and allowances for unusual or special radiation work conditions that may be encountered. This report provides specific guidance for the design of radiation shields in new facilities.

Because most new facilities will have a large number of systems or process modules containing radioactive materials, it is necessary to establish both preliminary and final shield design criteria. Initially, individual system design engineers need both guidance and a considerable degree of freedom to develop an optimum design. There must, of course, be assurance that the overall facility design can be safely and economically operated within the established radiation limitations. The preliminary design criteria established here are intended for that nurpose. When the preliminary design is completed, it will then be necessary to carry out an integrated evaluation of the shielding throughout the facility. The final design criteria described here are intended to reveal any inconsistencies, and to assure that balanced consideration is given to the design of radiation shields throughout the facility.

Using the dose rate of 0.5 mrem per hour (average) cited in ERDAM Appendix 6301 [Part II, B.6.f(1)], it might seem reasonable to design all shields to reduce radiation levels in work locations to about this value. On the basis of 2000 working hours per year, the annual dose to each radiation worker would be about $1000 \mathrm{mrem}$, which is the design basis annual dose for facility personnel. However, experience has shown that a considerable portion of various craft of skill yroup exposures occur in higher radiation exposure areas as a result of both reguiar and unscheduled (but anticipated) work required to keep the facility operating. Therefore, shielding requirements must provide for that portion of total exposure required for projected and anticipated inspections, adjustments, and repairs for each year of operation.

In addition, where experience indicates that the occurrence of abnormal or unanticipated events is probable within the design lifetime of the facility, 
Page 5

the resulting personnel dose must be considered in determining if the design meets the annual dose criterion. Random events of low probability which fall outside this time reference are not considered to be within the ERDAM guideline for facility design. However, it would be prudent engineering practice to assure that the design will allow recovery from such events.

Considering the above information, it might appear realistic to reduce the design dose rate in routine radiation work locations to a fraction of 0.5 mrem per hour, say 0.2 mrem per hour. However, when radiation sources of varying size, shape, and magnitude exist in a facility, economic optimization usually dictates establishment of various controlled zones, radiation zones and administrative controls to limit personnel dose. For example, expensive and massive shields may not be necessary if a radiation source is transient and system design does not require that facility personnel be nearby when the source is present. For transient sources, consideration should be given to designing for remote operation and/or the use of temporary shields. In general, there is a strong incentive to keep radiation levels conservatively low in areas known to require frequent or long occupancy, reserving a substantial fraction of available exposure for radiation zones that are entered infrequently and that are difficult and expensive to shield. The practical design level for any given radiation zone depends upon the occupancy requirements established for that zone. It is the intent of this report to provide design guidance for established controlled zones and radiation zones throughout any new facility.

Definitions

Controlled Access Area: Any area, access to which is controlled for purposes of protection of individuals from exposure to radiation and radioactive materials.

Uncontrolled Area: Any area where access is not controlled for purposes of protection of individuals from exposure to radiation and radioactive materials.

Normally Inaccessible Area: Any radiation zone to which access is not normally permitted because of radiation exposure considerations. Access may be permitted under certain emergency conditions.

Controlled Zones: Controlled access areas adjacent to radiation zones. such as corridors, hallways, offices and control rooms. They normally have very low radiation levels and serve as "buffer zones" between uncontrolled areas and 
Page 6

radiation zones. Entry is controlled by the provisions of a building or facility operating procedure.

Radiation Zones: Controlled access areas containing radioactive materials or radiation generating machines. Entry is controlled by the provisions of a specific radiation work procedure (RWP).

Radiation Work Procedures: Written procedures describing the type and quantity of radioactive material (or characteristics of a radiation generating machine), the kind and scope of work operations, protective equipment and protective measures required to enter a radiation zone and perform radiation work.

ALARA: In reference to radiation work, is defined as performing the work in such a way that the resulting radiation dose to personnel is "as low as reasonably achievable".

Dose Equivalent: Defined as the product of absorbed dose (rads) multiplied by quality factor, distribution factor, and any other modifying factors necessary to express on a common scale the irradiation incurred by persons. The unit of dose equivalent is the rem.

Application of Definitions

For the purpose of building design, the following types of rooms are to be uncontrolled areas: Tunchrooms, restrooms, administrative and clerical offtces, halls and corridors (outside process areas), nonprocess storage facilities, meeting rooms, and similar soace. These areas are to be shielded to reduce the calculated dose rate to below 0.1 mrem per hour, both during normal operation of the facility and during shutdown activities. By requiring the radiation level to be below 0.1 mrem per hour in these areas, the annual dose received by a member of the facility staff not engaged in actual radiation work will be limited to less than $5 \%$ of the DOE annual limit for radiation workers. Such a value is consistent with the DOE limit and policy for individuals in uncontrolled areas.

In an operating facility, controlled access areas (controlled zones or radiation zones) are established as required to provide administrative control over both the dose rate and the integrated dose received by workers. For design purposes, radiation zones are those areas to which access will be under the control of radiation work procedures (RWPs). Controlled zones are areas which serve as buffer zones between uncontrolled areas and radiation zones. 
Page 7

In general, all areas in which radioactive materials are processed, stored, or transferred will be radiation zones. In addition, all regions in which the radiation level exceeds 0.2 mrem per hour will be set off as controlled zones. A11 of the regions within the operating areas of new facilities are to be either controlled zones, radiation zones or normally inaccessible radiation areas.

It is not necessary that the radiation level throughout a given radiation zone be independent of time and position. A radiation zone may contain a number of local sources requiring separate exposure time control in their vicinity. The design radiation level should, to a first approximation, and considering radiation requirements only, be inversely proportional to the occupancy requirements. That is, a work area that is to be routinely and continuously occupied needs to be shielded to provide very low radiation levels, whereas significantly higher levels are acceptable in an area that is to be entered only at infrequent intervals and for short periods of time. Examples of the latter are sample or operating galleries that may be entered once each shift to obtain samples, record readings, make equipment adjustments, and occasionaliy perform maintenance.

Although it is theoretically possible to perform radiation work in any radiation field and still maintain personnel dose within DOE limits, operating experience in a number of nuclear facilities indicates that it is impractical to work in radiation fields significantly greater than 1000 mrem per hour. At higher radiation levels, a large fraction of the allowable dose can be received in approaching the work site, picking up and adjusting tools, examining the work site to determine how to accomplish the job, and in withdrawing from the area. Therefore, for design purposes, any zone in which the design radiation level exceeds 1000 mrem per hour will be considered inaccessible. If entry into a particular zone is to be required for any reason, e.g., inspection or nonroutine maintenance, the zone must be shielded to provide a design level of $1000 \mathrm{mrem}$ per hour or less. The maximum design value of 1000 mrem per hour is chosen to provide a realistically useful minimum access time. In some cases, the most effective design may incorporate movable shielding structures. Such equipment can have practical advantages in reducing radiation to acceptable levels during certain operation or maintenance functions. The design bases are intended to provide a facility that can be 
Page 8

operated safely and economically within the limitations imposed by DOE Order 5480.1, Chapter XI and ERDAM 6301. However, the operator of the facility will be expected to utilize available radiation dose in the most effective way. (See discussion in Appendix 2).

\section{Inital Criteria}

Initial design criteria are needed by individual system design engineers to assure that realistic shields are incorporated throughout the facility. Because of the cost impact of excessive shielding on the design, the design should not be overly conservative. At the same time, both the DOE policy of ALARA and the DOE exposure limits must be considered. The following criteria are to be used for the preliminary design of systems to assure that a realistic final design is achieved. In a 11 cases, the dose rates are to be determined at the point of personnel exposure. For shielded gloveboxes, this would be at the surface of the shielding. For large shielded hot cells, the design level dose rate is at 12 inches from the shield surface. 0ther situations are to be determined from operational usage of the equipment.

1) Controlled areas that are to be occupied at all times:

0.2 mrem per hour - initial design level

0.5 mrem per hour - maximum

Typically, process and heating, ventilating and air conditioning (HVAC) control rooms are manned at all times. For this reason, the basic design radiation level within such areas should be 0.2 mrem per hour, which allots about 400 mrem per year to each operator who is assigned to these areas on a full-time basis. This leaves most of the operators' annual dose available for situations which exceed the basic design dose rate. Such activities may include the receipt and unloading of radioactive materials, the packing and shipping of radioactive materials, providing liaison with maintenance personnel performing high radiation-level work, ind so on. If, on the other hand, the basic level in the control rooms were as much as 0.5 mrem per hour, the average operator would reach the annual design basis limit of 1000 by just being in the control room. An individual would greatly exceed this limit by also performing a significant amount of work in higher radiation fields.

2) Controlled areas requiring access for less than 1 hour per day:

2 mrem per hour - initial design level

5 mrem per hour - maximum 
Page 9

Radiation zones that will require access for relatively short periods of time, but on a routine basis (such as reading instruments, adjusting equipment settings, carrying out routine maintenance or inspection, etc.) can have higher radiation levels. A basic design radiation level of 2 mrem per hour is established for these zones on the basis that an average of less than 1 hour of access per day will be required. The annual exposure to each individual who receives the maximum design exposure at a rate of 2 mrem per hour in one of these areas would be 500 mrem.

3) Controlled areas requiring access for less than one hour per week: 10 mrem per hour - initial design level

20 mrem per hour - maximum

Some radiation zones might not require daily entrance but on a design basis need to be entered routinely for inspection or special maintenance. If it is established that such entries will require an average of less than one hour per week in the zone to carry out necessary functions, then the basic design radiation level can be set at 10 mrem per hour. At an exposure rate of 10 mrem per hour, a worker could receive up to 500 mrem per year in performing work in a radiation zone of this type.

4) Controlled areas requiring access for less than 5 hours per year: 100 mrem per hour - initial design level 200 mrem per hour - maximum

Any radiation zone to which access is desired to carry out infrequent, but routine inspection or special maintenance is to be shielded to a basic design radiation level of 100 mrem per hour. On the basis that an average of less than 5 hours of access per year will be required, the annual exposure to each individual who receives exposure at a rate of $100 \mathrm{mrem}$ per hour in one of these areas would be 500 mrem.

5) Controlled areas requiring access for less than 1 hour per year: 500 mrem per hour - initial design level

1000 mrem per hour- maximum

Some radiation zones may require occasional access to carry out unusual and infrequent inspection or breakdown maintenance. Such areas are to be shielded to a basic design radiation level of 500 mrem per hour. As indicated previously, it is impractical to work in radiation fields greater than about 1000 mrem per hour because of the inefficient expenditure of personnel dose. 
Page 10

A radiation level of 500 mrem per hour would make it operationally and administratively possible and practical to accomplish limited but realistic amounts of work within these zones. For actual entry into such a zone for 1 hour per year, an individual would receive 500 mrem per year.

For design purposes, radiation dose rates from transient sources may be equated to the design level dose rates. That is, if a transient source is to be present for up to five hours per year, the shielding for that source should be designed to allow a maximum dose rate of 100 mrem per hour. Similarly, if a transient source is to be present for up to one hour per week, the shielding for that source should be designed to allow a maximum dose rate of 10 mrem per hour.

\section{Final Design Criteria}

The following relation will be employed as the final shield design criteria for the facility:

$$
\sum_{i} \frac{H_{x i} R_{i}}{N_{x}} \leq 1000 \text { mrem per year per individual }
$$

Where the summation is over the $i$ different controlled zones and radiation zones that are established throughout the new facility, $\mathrm{H}_{x i}$ is the total number of hours per year that all persons in craft or skill group $x$ will spend in the $i$-th radiation zone whose design intensity is $R_{j}$ mrem per hour and $N_{X}$ is the number of members in the operating and maintenance crew who belong to craft or skill group $x$. The value of 1000 mrem per year per individual must include appropriate provision for exposure to airborne activity where applicable.

These relations can be applied during preliminary design of the facility as soon as the size of the operating and maintenance crew is established, including the composition by craft or skill group, and when facility personnel, in conjunction with individual systems engineers, establish access requirements for each radiation zone by craft and skill group. It is not anticipated that major adjustments will be required in the final design of radiation zones. However, this technique will reveal any gross imbalances that might otherwise be overlooked. These imbalances are expected to occur only if an unusually 
Page 11

high demand for radiation work is indicated for a particular craft or skill group. For example, the number of pipfitters required on the maintenance crew might be small, but most of their time might be utilized on high-level radiation zones. The final design would need revision to eliminate such an inconsistency.

\section{Criteria for Radiation Beams}

In the practical design of shields, it is frequently necessary to provide penetrations for operating equipment and to employ discrete shield sections or pieces, rather than solid homogeneous units. The discrete nature of the shield can influence the attenuation characteristics for radiations of interest. Of particular concern is the space that is required between surfaces to permit movement, such as between a fixed shield section and a removable or rotating plug. For the design of new facilities, the following guidelines are to be employed for the design of penetrations through shields that introduce radiation beams into controlled access areas.

1) The calculated intensity of the beam shall not exceed ten times the eye-weighted design level, where the eye-weighted design level is the design radiation level for the particular radiation zone divided by the beam intercepted by a sphere with a cross sectional area of one square centimeter.

2) The calculated intensity of the beam shall not exceed $930 \pi$ times the body-weighted design level, where the body-weighted design level is the design radiation level divided by the beam area intercepted by a sphere with a cross-sectional area of $930 \pi$ square centimeters.

Both of these criteria must be applied to each penetration and modifications incorporated in the design until they are met.

Basis for Beam Criteria

The limits established by the DOE are the same for irradiation of the lens of the eye, the gonads, and active blood-forming organs as for the whole body, the head and trunk. Based on this, it can be assumed that some consideration must be given in shield design to beams whose areas are comparable to that of the smallest listed part of the body, namely, the lens of the eye. The following rationale was employed to derive the two beam criteria for use in the design of new facilities. 
1) The lens of the eye has a cross-sectional area that is of the order of one square centimeter. In the normal movement of a working individual, it would not be expected that the lens of the eye would remain directly within a small beam; therefore, a weighting factor of ten is introduced to account for the average time spent by the lens in the beam.

In equation form:

$$
I(\text { beam }) \leq 10 I \text { (design) }
$$

where I (beam) is the radiation level of the beam in mrem per hour, and I (design is the basic design radiation level of the shield in mrem per hour. For small beams which might occasionally impinge upon the lens of the eye, the calculated beam radiation level would be 1 imited to 10 times the design radiation level for the controlled access area.

2) In addition to considering small organs, it is also necessary to consider the whole body irradiation that might be incurred as a result of a beam. For this purpose, it is assumed that a standard man can be represented by a sphere with a one-foot radius. As in the case of the eye, it is assumed that the body will not remain stationary in the beam, but will move in order to receive a volume average effect. It is assumed that it is tolerable to permit a beam dose equal to the basic radiation dose for the zone. Under this assumption, if a worker was intercepted by a bean the entire time spent within the particular controlled access area, his dose would be limited to twice the value he would have received had he not been in the beam. Such a beam allowance is considered to be realistically conservative. Consideration is given to the area of the beam that would be intercepted by the body, which is approximated by the one-foot radius sphere. In equation form:

$$
I \text { (beam) } \leq \frac{I \text { (design) A (body) }}{A(\text { beam })}
$$

where $A$ (beam) is the area of the beam, in square centimeters, intercepted by a one-foot radius sphere, $A$ (body) whose cross-sectional area is $930 \pi$ square centimeters. For beams whose cross-sectional areas exceed $930 \pi$ square centimeters, the calculated beam radiation level would be limited to the same value as the design radiation level for the controlled access area. 
APPENDIX 1

INTERNAL DOSE CONSIDERATIONS

Where there is a strong potential for internal deposition of radionuclides consideration must be given to the resulting dose in the summation of the design basis dose of $1000 \mathrm{mrem}$ per year per individual. This will require knowledge of the radionuclides which may be involved, the maximum permissible body burden (MPBB), the predicted rate of deposition, and the resulting exposure rate. In most cases, the MPBB for the whole body will be used. However, there will be some cases in which the radionuclides deposit in one or two discrete organs, and use of the MPBB for those organs may be desirable.

Use of internal deposition data in design should be conservative. That is, the resulting radiation doses should be generously estimated. Available internal dosimetry methods lack the necessary sensitivity for determinations of body depositions below about 5\% of the MPBB for a number of radionuclides of interest, plutonium-239, for example. Although this is a small fraction of the MPBB, the resulting dose represents a large fraction of the $1000 \mathrm{mrem}$ per year per individual used as the design basis limit. To avoid a serious impact upon allowable dose, design efforts should emphasize structures and arrangements which minimize or el iminate the potential for internal deposition.

As an example, if $5 \%$ of the MPBB were allowed for internal whole body dose from airborne contamination, this would require allotting a dose of $250 \mathrm{mrem}$ per year per individual for internal dose. Subtracted from the $1000 \mathrm{mrem}$ per year per individual available as the design basis annual dose, this would leave only 750 mrem per year per individual available for exposure to external sources of radiation. The resulting impact upon shielding requirements would be considerable. Therefore, it is important to reduce the potential for internal deposition to an absolute but realistic minimum. 
APPENDIX 2

OPERATING CONDITIONS

Designs of new facilities must be within the design basis limit of 1000 mrem per individual per year stated in DOE Order 5480. 1 Chapter XI and ERDAM Appendix 5301 [Part II, B.6.f(1)]. However, facility operators will utilize the occupational exposure limits stated in DOE Order 5480.1 Chapter XI. This provides for an annual whole body dose of up to 5000 mrem per year.

In an operating facility, it is necessary to establish administrative procedures to control the radiation dose of workers within the occupational limits established by the DOE. These administrative procedures include establishing methods and controls for performing work in radiation zones, establishing methods for measuring the radiation dose received by individuals, providing and maintaining supplies of protective clothing and equipment, monitoring for ususual or off-standard conditions, and maintaining personnel dose records. A commonly-used administrative procedure is that of limiting the monthly or single event dose received by an employe (HEDL manual, WHAN-M-8, Procedure 2.1.2). The main purpose of limiting dose received during short periods is to assure that an employe will be able to work in controlled areas throughout the year without exceeding any of the limits cited in DOE Order 5480.1, Chapter XI. If such administrative controls were not applied, all of the personnel in a facility might reach their quarterly dose limit within a month, or their annual dose limit within the first two quarters of the year, leaving no available dose for radiation zone work for the rest of the exposure period. Such a situation would be unacceptable. If an employe's average dose is maintained within 100 mrem per week, he would not exceed the annual whole body limit of 5000 mrem. However, the DOE policy on maintaining personnel dose "as low as reasonably achievable" (ALARA) places an additional responsibility on both operating management and design personnel to find ways to reduce employe exposure to the lowest levels that can be economically and practically achieved.

Since the allowable annual dose stated in design criteria is different from the allowable annual dose stated in the occupational exposure limits, it is important that the two are not mistakenly used in the wrong context.

Using the five normal access zone categories in Table I, and controlling exposure within the 1000 mrem per year design criterion, an average worker might be expected to have an exposure experience similar to the following 
(using the minimum dose rate values in each category):
$1 / 2$ hour
(. $500 \mathrm{mrem} / \mathrm{hr}$
$=250 \mathrm{mrem}$
2 hours
(a) $100 \mathrm{mrem} / \mathrm{hr}$
$=200$ mrem
10 hours
(c) $10 \mathrm{mrem} / \mathrm{hr}$
$=100 \mathrm{mrem}$
29 hours
(.) $2 \mathrm{mrem} / \mathrm{hr}$
$=58 \mathrm{mrem}$
1958-1/2 hours
0 $0.2 \mathrm{mrem} / \mathrm{hr}$
= 392 mrem
Total dose in 2000 hours
1000 mrem

Using the same normal access zone categories in Table I, and the maximum access time allowed in all four of the higher categories would result in worker exposure greatly in excess of the $1000 \mathrm{mrem}$ per year design criterion, as follows (minimum dose rate values in each category):

$\begin{array}{lll}1 \text { hour } & 0500 \mathrm{mrem} / \mathrm{hr} & =500 \mathrm{mrem} \\ 5 \text { hours } & 0100 \mathrm{mrem} / \mathrm{hr} & =500 \mathrm{mrem} \\ 50 \text { hours } & \text { o } 10 \mathrm{mrem} / \mathrm{hr} & =500 \mathrm{mrem} \\ 250 \text { hours } & \text { ? } 2 \mathrm{mrem} / \mathrm{hr} & =500 \mathrm{mrem} \\ 1694 \text { nours } & 0.2 \mathrm{mrem} / \mathrm{hr} & =339 \mathrm{mrem}\end{array}$

Total dose in 2000 hours

2339 mrem

The latter case is not acceptable for design purposes. To assure staying within the design critarion of 1000 mrem per year per individual, it will be necessary to make a detailed review of each facility to determine how many of each type of zone will be required by the systems engineers of that facility. Without such a review, it would be impossible to establish how many operators, millwrights, pipefitters, electricians, etc. will be required in the operating and maintenance crew. If, for example, there are many high-level radiation zones that require entry by personnel of a particular craft or skill group and there are few Dersons of that group in the work crew, then the dose to these persons will exceed the average dose to facility personnel. For this reason, it will be necessary to make adjustments during final design to assure that the facility is operable from the radiological standpoint. 
Appendix 2

Page 3

If actual operating experience in the facility results in personnel doses significantly greater than the design criterion of 1000 mrem per year per individual, the original design is inadequate. This assumes of course, that the processes carried out in the facility are those for which the facility was designed, and the work in the facility is performed in accordance with standard operating procedures and applicable radiation protection procedures. 


\section{REFERENCES}

1. DOE Order 5480.1 , Chapter XI

2. ERDA Manual Chapter 6301 Appendix, 1977

3. Title 10, Code of Federal Regulations, Chapter I, Part 20,1980

4. Recommendations of the International Commission on Radiological Protection, ICRP Publication 26, 1977

5. Basic Radiation Protection Criteria, National Council on Radiation Protection and Measurements, NCRP Report No. 39. 1971

6. Radiation Protection Procedures, Hanford Engineering Development Laboratory manual, WHAN-M-8, 1976 